\title{
Omics Methods for Probing the Mode of Action of Natural and Synthetic Phytotoxins
}

\author{
Stephen O. Duke • Joanna Bajsa • Zhiqiang Pan
}

Received: 31 October 2012 /Revised: 20 December 2012 / Accepted: 31 December 2012 /Published online: 27 January 2013

(C) The Author(s) 2013. This article is published with open access at Springerlink.com

\begin{abstract}
For a little over a decade, omics methods (transcriptomics, proteomics, metabolomics, and physionomics) have been used to discover and probe the mode of action of both synthetic and natural phytotoxins. For mode of action discovery, the strategy for each of these approaches is to generate an omics profile for phytotoxins with known molecular targets and to compare this library of responses to the responses of compounds with unknown modes of action. Using more than one omics approach enhances the probability of success. Generally, compounds with the same mode of action generate similar responses with a particular omics method. Stress and detoxification responses to phytotoxins can be much clearer than effects directly related to the target site. Clues to new modes of action must be validated with in vitro enzyme effects or genetic approaches. Thus far, the only new phytotoxin target site discovered with omics approaches (metabolomics and physionomics) is that of cinmethylin and structurally related 5-benzyloxymethyl1,2-isoxazolines. These omics approaches pointed to tyrosine amino-transferase as the target, which was verified by enzyme assays and genetic methods. In addition to being a useful tool of mode of action discovery, omics methods provide detailed information on genetic and biochemical impacts of phytotoxins. Such information can be useful in understanding the full impact of natural phytotoxins in both agricultural and natural ecosystems.
\end{abstract}

Keywords Allelochemical $\cdot$ Herbicide $\cdot$ Metabolomics . Mode of action · Omics · Physionomics · Phytotoxin . Proteomics $\cdot$ Transcriptomics

S. O. Duke $(\square) \cdot$ J. Bajsa $\cdot$ Z. Pan

NPURU, USDA, ARS, P. O. Box 8048, University, MS 38677, USA

e-mail: stephen.duke@ars.usda.gov

\section{Introduction}

Understanding the modes of action of natural compounds as toxicants is important for at least two reasons. From an ecological and evolutionary standpoint, knowing the mode of action of such compounds is critical to understanding the function of the compound in nature. For example, the high activity of phytotoxins from plant pathogens on specific molecular targets found in green plants, but not in fungi, provides strong evidence that the compounds have evolved as virulence factors for the pathogens (Duke and Dayan, 2011). From a more practical standpoint, natural compounds often have been the source of pesticides with new modes of action (Dayan et al., 2012), and new modes of action are needed to combat the increasingly rapid evolution of pest resistance to the currently used pesticides, particularly herbicides (Duke, 2012). There are only about 20 molecular targets for the herbicides currently used (Duke, 2012), but natural phytotoxins have many effective modes of action that are not used by commercial herbicides (Duke and Dayan, 2011).

Exploitation of a natural product mode of action may or may not involve the use of the natural products as a chemical scaffold for the design of synthetic compounds that have the same mode of action. For example, the allelochemical leptospermone was the chemical basis for the design of the structurally similar triketone herbicides that inhibit hydroxyphenylpyruvate dioxygenase (HPPD) (Beaudegnies et al., 2009), the last commercial herbicide mode of action introduced (Duke, 2012). However, the phytochemical ryanodine only gave the clue for the new insecticide mode of action (targeting ligand-gated calcium channels of insect muscles), for which structurally unrelated insecticides have been developed and commercialized (Lahm et al., 2009). The modes of action of most natural phytotoxins are unknown, especially for compounds thought to be involved in plant/plant interactions (allelochemicals). 
Determination of the mode of action of a phytotoxin is often a daunting task. There are many papers purporting to show the mode of action of herbicides and natural phytotoxins that have turned out to be wrong. Most of these papers describe secondary and tertiary effects of the compounds. There is no detailed and sure procedure for determination of the mode of action of a phytotoxin, although there are papers that will give researchers a start by using simple physiological assays (e.g., Dayan et al., 2000; Dayan and Watson, 2011; Dayan and Zaccaro, 2012).

Omics methods (genomics paired with transcriptomics and proteomics, as well as metabolomics, and physionomics) offer new approaches to narrowing the search for the molecular target of a toxicant. Robust technology for the first three of these approaches has only become available during the past decade, as evidenced by the fact that virtually all of the papers cited in this review have been published during the past 10 years. Similar strategies generally are used in the utilization of all of these approaches for mode of action research. Genomics underpins transcriptomics and proteomics, but genes are fixed, and treatment with a toxin does not change this. However, reverse genetics, that is determination of gene function by analysis of phenotypic effects of gene expression, is important in annotation of sequenced genes. Affecting plant gene expression with phytotoxins can be valuable in this endeavor.

The simplest method to use omics methods to probe the mode of action of a phytotoxin is to simply examine the effect of the compound on profiles of mRNA, proteins, metabolites, or physiological processes at different doses and at different times after administering the dose and look for a hint about the molecular target. This approach has not been very productive, as the complexities of the responses to a toxicant at any level seldom reveal its initial target. Even when the mode of action is known, this approach does not always point unambiguously to that target. The other and more rigorous approach is to generate a complete database of responses to a library of toxicants with known molecular targets. Then, the detailed response to a compound with an unknown target can be compared with responses of plants to compounds with known targets. This approach can indicate or eliminate a known target site. If the omics data do not fit known modes of action, they may suggest a new molecular target. Confirmation of the target site can only be accomplished by biochemical or genetic approaches. Unfortunately, few labs other than industrial ones have the capacity to generate and analyze large databases for all of the known modes of action.

In this short review, we discuss the most commonly used omics approaches for the study of mode of action, giving the advantages and limitations of each.

\section{Transcriptomics}

Profiling of a global transcriptional response to a toxicant can be determined readily with the microarray or next generation sequencing technologies that have become available relatively recently. Transcription profiling is used extensively in combinations with other methods to determine the mode of action of pharmaceuticals (e.g., Bharucha and Kumar, 2007; Gobert and Jones, 2008; Pan et al., 2008). Inhibition of an enzyme involved in a critical biochemical pathway or other protein receptor (e.g., the D-1 protein of photosystem II (PSII)) by a chemical inhibitor should result in compensation through alteration of the transcription of genes encoding enzymes of the directly affected pathway, as well as genes encoding proteins associated with stress and with inactivation of xenobiotic compounds by chemical alterations. Genomic information, coupled with microarray technology or next generation sequencing, allows us to readily examine the relative effect of an inhibitor on every gene in a genome. To get maximal information, the target plant should be one for which the genome is well annotated. The first plant species for which this information was available was Arabidopsis thaliana, and, accordingly, most of the first papers on global transcriptional responses to phytotoxins used this species for such studies (e.g., Lechelt-Kunze et al., 2003; Manfield et al., 2004; Baerson et al., 2005; Raghavan et al., 2005, 2006; Gershater et al., 2007; Manabe et al., 2007; Das et al., 2010,). The relatively small genome of $A$. thaliana reduces the amount and complexity of data that must be analyzed. The genomes of other plant species are becoming available at an increasing rate, and the annotations of those genomes are becoming more robust. Some have argued that even though $A$. thaliana has not been a good plant species for discovery of new herbicide target sites by knocking out genes, it should be good for elucidating the mode of action of new phytotoxins to which it is sensitive by using functional genomics and metabolomics (Gressel, 2009). At this time, the small genome, superior gene annotation, and rapidity with which experiments can be done with $A$. thaliana make it the best model organism for mode of action transcriptome fingerprinting.

The transcriptome response is differentially affected by different doses of the phytotoxin, and the effects change over time. So, some uniform method of treatment must be used when generating a transcriptome response library to phytotoxins with different modes of action, such as treatment with the $\mathrm{I}_{50}$ and/or $\mathrm{I}_{80}$ (concentrations required for 50 or $80 \%$ inhibition of growth) dose of the toxicant, with sampling at various times after the beginning of exposure. Still, different compounds act at different rates due to several factors, including target sites, metabolic inactivation rates, uptake rates, and translocation rates. To complicate things even more, some phytotoxins act primarily on 
meristems (e.g., mitotic inhibitors) and others act almost exclusively on green, photosynthesizing tissues (e.g., PS II inhibitors) (Fedtke and Duke, 2005). So, there is no perfect way to have a uniform method of building a transcriptome response library for phytotoxins with known molecular target sites. These problems also are true for other omics approaches to studying modes of action.

A good example of the difficulties is that of the work on the transcriptional responses of $A$. thaliana to the allelochemical benzoxazolin-2-(3H)-one (BOA) (Baerson et al., 2005). The original intent of this work was to provide indications of the mode of action of this compound. From a dose-response experiment, the $\mathrm{I}_{50}$ and $\mathrm{I}_{80}$ concentrations of BOA on root growth of 10-day-old A. thaliana seedlings were determined, and the transcriptome responses of the seedlings were determined by whole transcribed genome microarrays at these two doses $24 \mathrm{hr}$ after treatment. At this time and at these doses, almost 200 genes representing 12 functional categories were affected 2.5 fold or more in one or both of the two doses. Genes involved with metabolism and cell rescue and defense accounted for more than half of the affected genes. Many of these genes encode detoxification enzymes that also were induced by a set of structurally diverse xenobiotic compounds with different modes of action. Non-phytotoxic xenobiotics that protect plants from herbicides (safeners) have similar effects on transcription of genes involved in phytotoxin detoxification in A. thaliana (Baerson et al., 2005; Skipsey et al., 2011). In the Baerson et al. (2005) study, there was no clear indication of association of any of the genes affected by BOA with a particular mode of action. Separating effects of genes closely associated with the target site from those resulting from metabolic perturbation and defense pathways is a daunting task. Genes affected at time points that will show earlier effects before the cascade of non-specific responses are more likely to be enriched in those more directly associated with a primary response.

Early work examined the effects of herbicides on a limited number of genes such as the studies of Glombitza et al. (2004), who examined the effects of two herbicide classes on 267 A. thaliana genes, and Pasquer et al. (2006), who studied the effect of herbicides from three chemical classes on wheat gene expression using a microarray with 600 barley cDNAs. To truly determine the action of a phytotoxin on the transcriptome, a microarray composed of most or all (global) of the genome of the plant being studied must be used. The rest of the examples discussed used such technology.

There are a number of papers on transcriptional responses to herbicides with known modes of action. The earliest paper to use a global gene chip to probe the mode of action of a herbicide was that of Lechelt-Kunze et al. (2003). A gene of $A$. thaliana encoding a putative fatty acyl-CoA reductase involved in long-chain fatty acid alcohol biosynthesis was up-regulated by two herbicides (flufenacet and benfuresate) that inhibit very-long-chain fatty acid elongases as their mode of action. Manfield et al. (2004) found several genes of $A$. thaliana that are closely associated with cell wall assembly to be involved in the mode of action of the cellulose synthesis-inhibiting herbicide isoxaben. Zhu et al. (2008) determined transcriptome responses of glyphosate-resistant $(\mathrm{R})$ and -susceptible $(\mathrm{S})$ soybean near isogenic varieties. The resistance was imparted by a transgene encoding a glyphosate-resistant target site enzyme (5-enolpyruvylshikimate-3-phosphate synthase, EPSPS). At 1, 4, and $24 \mathrm{hr}$ after treatment, 3, 170, and 311 genes were affected at these times, respectively, in the $\mathrm{S}$ variety, and 1,4 , and 24 genes were affected, respectively, in the $\mathrm{R}$ variety. The authors concluded that there were no major transcriptomic changes with the $\mathrm{R}$ variety. The genes affected in the $\mathrm{S}$ variety would not have pointed clearly at EPSPS as the target site of glyphosate. There was no effect on transcription of EPSPS at any time point, and the only gene of the shikimate pathway affected was that of 3deoxy-D-arabino-heptulosonate-7-phosphate synthesis, the first enzyme of the pathway. This effect was seen only at $4 \mathrm{hr}$. Three other genes associated with aromatic amino acid metabolism were slightly affected, but no more so than many other unrelated genes. The results of this paper would probably not have been useful in discovery of the target of glyphosate if it were not already known. However, it did support the view that glyphosate has no other target site than EPSPS, in that there were no major transcriptome effects of glyphosate in the $\mathrm{R}$ variety.

In a similar paper, Manabe et al. (2007), using imidazolinone herbicide- (inhibitors of acetolactate synthase, ALS) susceptible and resistant (via a mutation in $\operatorname{csr} 1-2^{D}$ that encodes a subunit of ALS) A. thaliana, found many genes affected by the herbicide in the S plants, whereas there were no significant changes to the transcriptome of treated $R$ plants. Nevertheless, the results would not have pointed the branched chain amino acid pathway as the site of the target of this type of herbicide. Das et al. (2010) reported that transcriptional responses to glyphosate compared to those elicited by a series of ALS inhibitor herbicides in $A$. thaliana and Brassica napus were quite different, so that one could differentiate between the two modes of action, as well as from other stress treatments. Three classes of ALS inhibitors were used (two sulfonylureas, one imidazolinone, and one triazolopyrimidine), and results suggested that the method could differentiate the between effects of compounds with the same molecular target, even when the compounds are from the same chemical family. They also reported that herbicidal inhibitors of PS I, PS II, phytoene desaturase, auxin transport, and gibberellin biosynthesis have distinctive transcriptional signatures.

Transcriptional responses to other phytotoxins with known modes of action include the work of Zhu et al. (2009) and Ramel et al. (2007) on the two PSII-inhibiting 
herbicides atrazine and bentazon, and of Raghavan et al. $(2005,2006)$ on 2,4-D. Kelley et al. (2006) found a strong transcriptional response of $G H 3$, a primary auxin-responsive gene, in soybeans to the auxinic herbicides dicamba and clopyralid. The gene was not significantly affected by heat, drought, and salt stress, nor by virus infection. Jamers and De Coen (2010) found strong transcriptional effects on Chlamydomonas reinhardtii genes associated with oxidative stress when the alga was treated with subtoxic levels of paraquat, a herbicide that causes all of its effect through rapid generation of reactive oxygen species.

There are very few papers on the transcriptional responses of plants to allelochemicals or other phytochemicals. We have already mentioned the work of Baerson et al. (2005) in which the main transcriptome responses were upregulation of stress genes and those associated with metabolic detoxification of xenobiotics. Chi et al. (2011) attempted to learn more of the mode of action of juglone (5-hydrox-1,4-napthoquinone) by transcriptome profiling. The major effects were on genes related to cell growth, cell wall formation, detoxification of xenobiotics, abiotic stress, and epigenesis. The mechanism of action of L-DOPA was probed by microarray (Golisz et al., 2011). The authors concluded that it has two mechanisms: 1) disruption of amino acid metabolism and 2) regulation of metal ion homeostasis, especially that of iron. However, no specific target sites were identified. Golisz et al. (2008) probed the transcriptome response of $A$. thaliana to fagomine, gallic acid, and rutin, all putative allelochemicals of buckwheat (Fagopyrum esculentum). Most of the responses were consistent with stress effects, but the target sites of the compounds were not identified. The natural phytotoxin cantharidin strongly affected transcription of the genome of $A$. thaliana, but this compound inhibits all 19 serine/threonine protein phosphatases of the plant (Bajsa et al., 2011a, b). These enzymes strongly influence many signaling pathways, and, thus, $10 \%$ of the genes of the A. thaliana genome were significantly affected within $24 \mathrm{hr}$ of exposure to a cantharidin dose that reduced chlorophyll levels by $30 \%$. A large number of genes were both down- and up-regulated, and the pattern of genes affected changed dramatically with time after treatment as seen by a hierarchical clustering of microarray data (Fig. 1). Similar results were found with endothall, a commercial herbicide that is a close chemical analogue of cantharidin, which also inhibits serine/threonine protein phosphatases (Bajsa et al., 2012). The natural phytotoxin coronatine, an analog of the hormone methyl jasmonic acid (MeJA), influenced $35 \%$ of the genes regulated by MeJA in tomato (Uppalapati et al., 2005). Just as found for cantharidin, analysis of transcriptome responses to coronatine revealed major effects on signaling via the jasmonic acid, ethylene, and auxin pathways. Coronatine and MeJA were concluded to share similar but not identical activities that impact multiple hormone pathways.

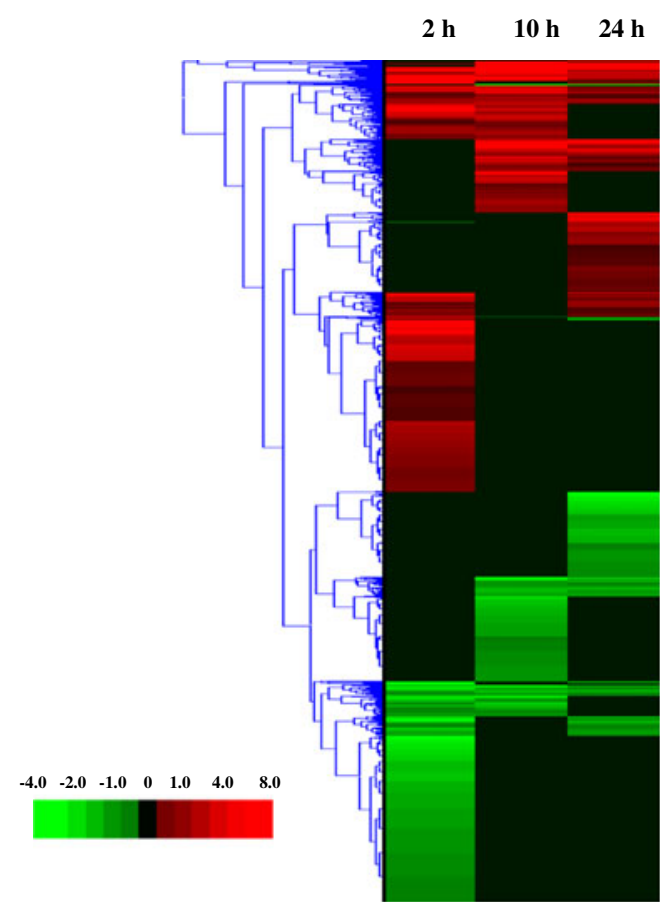

Fig. 1 Hierarchical clustering of microarray data (heat map) from the analysis of Arabidopsis thaliana genes which changed expression 2, $10,24 \mathrm{hr}$ after treatment with $200 \mu \mathrm{M}$ cantharidin. Previously unpublished data from the experiments reported by Bajsa et al. (2011a)

The phytotoxic trichothecene deoxynivalenol (DON) produced by the plant pathogen Fusarium graminearum had distinct effects on transcription in barley (Gardiner et al., 2010). Transcripts for ABC transporters, UDP-glucosyltransferases, cytochrome $\mathrm{P} 450 \mathrm{~s}$, and glutathione- $S$-transferases were upregulated. Cysteine synthase genes were dramatically upregulated. Biochemical studies supported the view that these upregulated genes were involved in detoxification of DON.

Transcriptome responses to a particular compound can vary considerably, depending on duration and method of treatment and dose(s) used. Therefore, such experiments should be done with more than one dose, and sampling should be done at several times after exposure. Since microarray methods do not provide quantitatively linear results, RT-qPCR (reverse transcription-quantitative real-time PCR) methods should be used to verify and obtain more accurate data on genes of interest identified with microarray methods (e.g., Baerson et al., 2005). Phytotoxins often target specific tissues, such as meristematic cells. Thus, extraction of RNA from an entire plant, root, or shoot may dilute a more clear response that would have been obtained from the target tissue(s) or cell type(s). Analysis of biosynthetic pathways, in addition to individual genes, may provide clearer hints to the mode of action of a toxicant. For example, although there were no profound effects of an array of ergosterol synthesis-inhibiting fungicides on any of the genes encoding enzymes of the ergosterol synthesis pathway in Saccharomyces cerevisiae, analysis 
of the pattern of effects on the entire pathway provided a signature that differentiated Class I and II ergosterol synthesis inhibitors from other fungicide modes of action (Kagan et al., 2005) (Fig. 2).

The whole transcribed genome microarray was a huge leap forward in transcriptome analysis (Redman et al., 2004). However, high-throughput, next generation sequencing of cDNA from mRNA or RNA-Seq offers another leap forward (Morozova and Marra, 2008; Wang et al., 2009; Marioni et al., 2008). With serial analysis of gene expression or massively parallel signature sequencing, the number of copies of transcripts from different genes is determined by sequencing cDNA fragments that are of sufficient length to identify the genes. These methods allow one to count directly the relative number of times a gene has been transcribed in a sample with statistical robustness. This method is much more precise than microarray methods, and it allows one to do transcriptomics experiments with plant species for which microarray chips do not exist. The dynamic range of this method is greater than 8,000 -fold,
Fig. 2 Effects of Class I (a), II (b), and III (c) sterol biosynthesis inhibitors, and a putative methionine biosynthesis inhibitor (cyprodinil, d) on expression levels of genes in the ergosterol pathway. Standard errors are shown in $\mathbf{a}$ and $\mathbf{b}$, and standard deviations are shown in $\mathbf{c}$ and $\mathbf{d}$. Genes are listed on the $\mathrm{x}$-axis from left to right in the order in which they appear in the pathway. The transcription relative to untreated controls is shown on the y-axis. Dashed horizontal lines on the graphs indicate the level of expression at which no change is seen relative to the control. Arrows indicate gene(s) encoding enzymes targeted by each inhibitor class. Reproduced from Kagan et al. (2005)

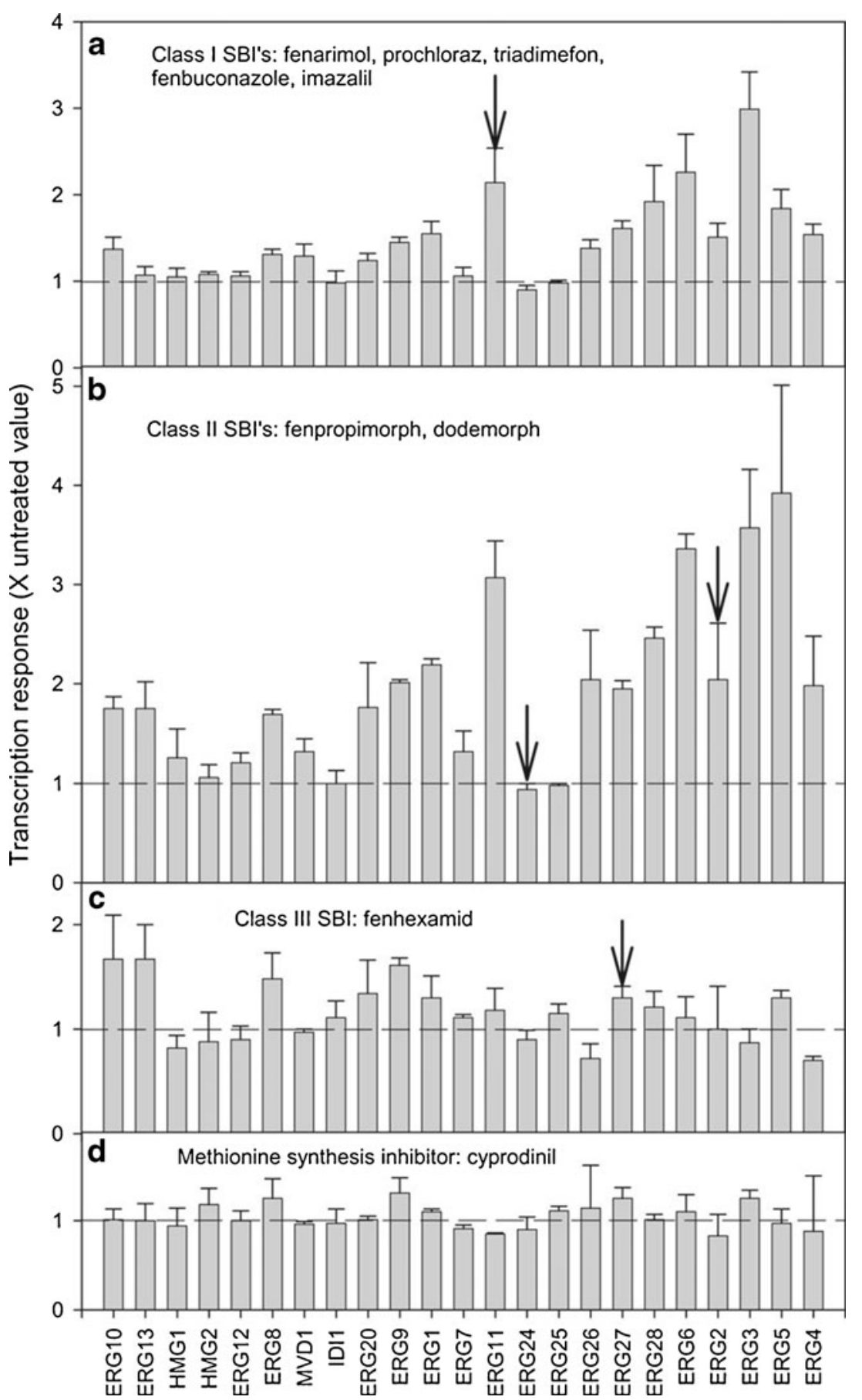


whereas that for microarray is only up to a few hundred-fold (Wang et al., 2009). As a result, RNA-Seq methods are much more accurate for both highly and poorly expressed genes than is microarray. A downside of this method is that many millions of cDNAs must be sequenced to determine definitive effects on weakly transcribed genes. However, this method provides the opportunity to obtain more accurate expression level estimates than can be obtained with microarray methods. Until recently, the expense of this approach has been prohibitive, but in the past few years, the cost has become competitive with microarray. We have seen no papers that use this method to probe the mode of action of phytotoxins.

There is a danger that RNA-based data can result in false conclusions about the influence of a phytotoxin on proteins resulting from transcriptional effects. Gene expression also is dependent on factors other than transcription, such as post-transcriptional processes, which can cause the protein levels to change independently of mRNA. This problem is discussed further in the Proteomics section below.

We are unaware of transcriptome information leading to the discovery of a target site of a phytotoxin, but there are numerous cases in which it has resulted in a better understanding the mode of action of phytotoxins (e.g., Zhu et al., 2008). If a transcriptional pattern is too complex, determinning what gene(s) might be associated with the primary target of the phytotoxin is challenging, even with RNASeq. As stated by Duke et al. (2009), transcriptional profiling can be useful in creating a list of candidate targets and pathways that is unmatched by any other technologies. This information can provide a foundation for the development of a hypothesis concerning the putative primary cellular target or targets of a phytotoxin.

\section{Proteomics}

Identification of proteins separated on two dimensional gels (2D PAGE) with mass spectrometric methods has allowed scientists to determine effects of phytotoxins on hundreds of proteins. There are thousands of proteins in plant cells, so this method is not as global as transcriptional analysis. Nevertheless, the effects on relative abundance of proteins are closer to actual physiological effects than are transcriptional responses. There are only a few papers on analysis of proteome responses of plants to herbicides, and only a couple of papers are available that use this method to probe effects of putative allelochemicals and natural phytotoxins.

Nestler et al. (2012) examined the effects of low and high doses of the herbicides paraquat (a PSI energy diverter), diuron (a PSII inhibitor), and norflurazon (a phytoene desaturase inhibitor) on the proteome of the green alga Chlamydomonas reinhardtii. Significant effects (both up- and down-regulation) were found on 149-254 proteins, depending on the herbicide. Effects were strong at low doses and at $6 \mathrm{hr}$ after treatment. There were a number of commonly affected proteins (e.g., ribosomal proteins). However, there were some proteins associated with specific modes of action. For example, although norflurazon had no effect on the abundance of its target enzyme, phytoene desaturase, other enzymes of the plastidic isoprenoid pathway (e.g., 1deoxy-D-xylulose 5-phosphate synthase and geranylgeranyl reductase) were upregulated, as were some enzymes of the tetrapyrrole pathway. In the case of diuron, the amounts of the D1 protein, its molecular target, and the light harvesting complex protein were increased, whereas levels of some other proteins involved in photosynthetic electron transport were decreased. Heat map analysis of effects of the three herbicides on proteins associated with photosynthesis showed distinct patterns of up- and down-regulation associated with each of the herbicides (Fig. 3).

Proteomic analysis of roots of Medicago truncatula treated with ALS-inhibiting herbicides flumetsulam and metsulfuron methyl revealed more proteins were affected in meristematic (81) than in non-meristematic (51) tissues (Holmes et al., 2006). There were two trends: 1) increased accumulation of proteins involved in cell division and redox mediation in meristematic than in other tissues, and 2) increases in proteins involved in pathogen responses and decreases in metabolic proteins in all tissues. These effects would not point to the molecular target site of these herbicides.

Kelley et al. (2006) found four proteins to be strongly affected by the two auxinic herbicides dicamba and clopyralid in soybeans. One of the proteins was the product of the GH3 gene. Although it was not detected by 2-D gel, this protein was probed by immunoblot analysis since the transcription of the gene was strongly upregulated (see transcriptomics section). Only three proteins were identified by 2-D gel analysis as strongly affected. They were tentatively identified as malate dehydrogenase (MD), gammaglutamyl-hydrolase, and superoxide dismutase (SOD). SOD is a stress protein that would be expected to be upregulated by phytotoxins for many modes of action, and MD upregulation has been associated with general plant stress. The upregulation of the $\mathrm{GH} 3$ gene and protein was suggested as a biomarker for auxinic herbicide damage.

Sublethal treatments of Vitis vinifera with the protoporphyinogen oxidase (PPO)-inhibiting herbicide flumioxazin caused abundance of 33 proteins to change (Castro et al., 2005). The herbicide up-regulated proteins associated with pathogenesis, oxygen stress, and photorespiration, whereas levels of some enzymes of carbon fixation and sugar metabolism were reduced. The authors speculated that reductions of some proteins may have been due to enhanced degradation of the proteins, a process that has been found to be an indirect effect of PPO inhibitor herbicides. 


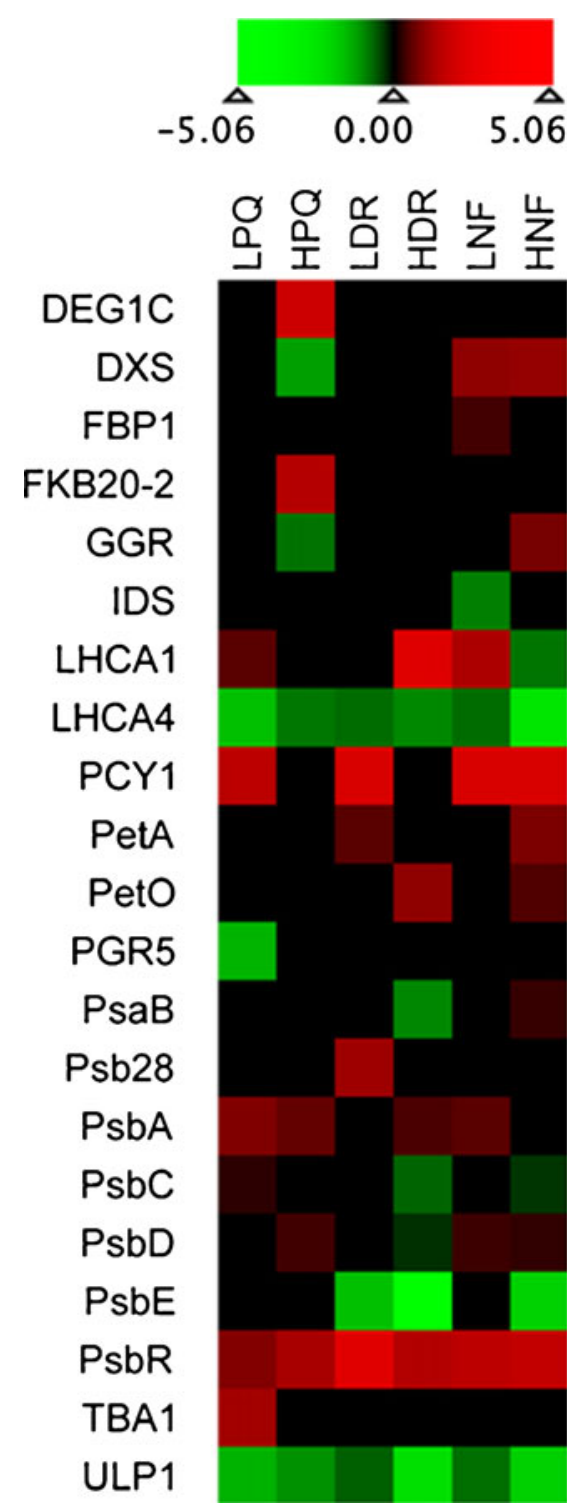

Fig. 3 Heat map showing proteins functionally related to the photosynthetic machinery which were significantly changed in Chlamydomonas reinhardtii in response to paraquat (PQ), diuron (DR), and norflurazon (NF) at high (H) and low (L) concentrations. Statistical evaluation was performed with G-test, fold changes are presented as $\log 2$ values. Reproduced from Nestler et al. (2012) with permission

Proteomic analysis of maize revealed that the microtubuledisrupting herbicide amiprophos methyl changed the amount of 28 proteins, allowing the detection of 15 additional proteins and disappearance of 13 proteins with 2-D gels (Wang et al., 2011). Some of the proteins affected in the root, leaves, and mesocotyl were a cold acclimation protein, ubiquitin, a ubiquitin-like protein, maturase $\mathrm{K}$, and a cytochrome $\mathrm{P} 450$ monoxygenase in the mesocotyl, ferredoxins and 2,4, dienoylCoA reductase of the root, and an ATP-dependent protease. They concluded that the profile of affected proteins could be used as a marker for phytotoxins acting through this mode of action.

The effects of the long chain fatty acid elongaseinhibiting herbicide dimethenamid and the herbicide safener cloquintocet-mexyl on the proteome of roots, leaves, and coleoptiles of Triticum tauschii were analyzed by Zhang et al. (2007). Mutually exclusive protein groups were affected by the two chemicals. Proteins increased by the safener were involved predominately in xenobiotic detoxification, mainly in the coleoptiles and root. Proteins induced by the herbicide were from several classes involved in stress responses. No multidrug resistance-associated proteins (MRP) were detected by 2-D gels, but enhanced safener-induced transcription of one MRP was found by RT-qPCR.

The effects of crude extracts of allelopathic Mexican plant species on the proteome of bean and tomato roots revealed alterations in only 11 to 16 proteins, depending on the source of the extract and test plant species (CruzOrtega et al., 2004). In these relatively early studies, only an $\alpha$-amylase inhibitor-like protein and glutathione $S$-transferase were identified as being affected. Both of their levels increased, but this provided few clues to understanding the physiological mechanisms of allelochemical-induced stress. We have not found any studies on the effects of single allelochemicals on the proteome.

$\mathrm{Li}$ et al. (2011) identified 25 differentially expressed proteins in a Chinese medicinal Achyranthes species treated with growth-promoting extracts of soil in which the same species was growing. Proteins associated with stress and secondary plant metabolism, signal transduction, synthesis and degradation of nutritive material, as well as synthesis and degradation of nucleic acids and protein were affected. This paper did not identify a target site, but the actual active compounds in the extract also were not identified.

Proteomics, using MS analysis of 2-D gel spots is not at the level of precision as transcriptomics, whether using microarrays or second generation sequencing. For example, the transcriptional clue that the $G H 3$ gene is up-regulated by auxinic herbicides could not verified by 2-D gel analysis, but was verified with a more sensitive immunochemical method (Kelley et al., 2006). The problems with proteomics outlined by Zhang and Riechers (2008) still largely exist. They include the lack of a template-based replication process such as PCR for RNA. This means that visualizing and analyzing low abundance proteins from gels is impossible with the methods that have been used. Reproducibility is a problem with 2-D gels (Abdallah et al., 2012). Additionally, proteomics is limited if gene or transcript information is not available to identify the sequenced peptides. The complexity of posttranslational modification of proteins and its regulation is a difficulty that is not encountered with RNA. Another drawback it that proteomics is limited to soluble 
proteins, excluding many membrane-bound proteins (Trimpin and Brizzard, 2009). In general, the correlation of transcriptomes and proteomes is not good, at least partly because actually translated RNA is only a part to the total RNA usually analyzed with transcriptomics methods. Using only polysomal RNA in transcriptional studies may reduce the lack of correlation (Skadsen and Jing, 2008). Recently developed gel-free proteomics methods such as iTRAG (isobaric tags for relative and absolute quantitation) and other protein tagging methods coupled with LC-MS/MS may become powerful tools for tackling such problems and improving on 2-D gel-based proteomics (Bindschedler and Cramer, 2011; Abdallah et al., 2012). Less complicated, lable-free, gel-free LC/MS methods also are available (Abdallah et al., 2012). We have found no literature using these newer proteomics methods to probe the mode of action of phytotoxins.

\section{Metabolomics}

Compared to the number of genes and/or proteins in a single plant species, there are a much smaller number of metabolites with a molecular weight less than 500, especially primary metabolites required for growth and development. If one includes secondary metabolites, all plant species combined have over 100,000 different compounds (Dixon, 2001), but most plant species contain less than a thousand primary metabolites and perhaps as many secondary metabolites, some of the latter of which are often exclusive to a single or a closely related group of plant species. Herbicides and other potent phytotoxins do not kill plants by interfering with secondary plant metabolism, so metabolomic approaches to understanding mode of action can concentrate on the relatively small number of primary metabolites. However, effects of phytotoxins on concentrations of some secondary compounds might be useful in generating a fingerprint for some modes of action.

Modern chromatographic separation instrumentation coupled with mass spectrometry and/or NMR allows the separation and tentative identification of most of these compounds with relative ease. One problem with this approach is that the concentrations of even primary metabolites can be orders of magnitude apart, and can vary dramatically between cell types and different tissues. Some metabolic intermediates are under tight regulation and do not exceed very low concentrations, as they can be toxic to the plant at higher concentrations. Examples of these toxic intermediates include sphingoid bases, protoporphyrinogen IX, and $\alpha$-ketobutyric acid (Abbas et al., 2002; Duke, 2012).

In this short review, metabolomics methods cannot be discussed in detail. These details can be found in more extensive reviews dealing only with metabolomics (e.g.,
Aliferis and Chysayi-Tokousbalides, 2011). One approach to metabolomics is to generate one-dimensional (1D) proton NMR $\left({ }^{1} \mathrm{H}\right.$ NMR) spectral fingerprints of crude extracts, hoping that the resulting information can provide clues to the mode of action, by comparing with fingerprints of phytotoxins with known modes of action (e.g., Ott et al., 2003; Aliferis and Chysayi-Tokousbalides, 2006). For obvious reasons, this method is inferior to actually identifying and quantifying each compound. Two-dimensional (2D) NMR with correlation spectroscopy (COSY) analyses of crude extracts can provide more chemical data, but the method is inferior to chromatographic separation, followed by mass spectroscopy. The advantage of the NMR method is its minimal sample preparation. LC-NMR has advantages over NMR alone, but it has limited detection limits compared to MS coupled with chromatography. Use of both GC-MS and LC-MS/MS for the same samples has provided perhaps the most definitive information on metabolomics thus far generated for herbicide modes of action (Grossmann et al., 2010, 2012a, b). There have been relatively few studies that use metabolomic approaches to mode of action discovery or confirmation for phytotoxins. The review of Aliferis and Jabaji (2011) gives details about the use of metabolomics to profile modes of action of pesticides, including herbicides. They note that this methodology is in its infancy for mode of action discovery.

The first use of NMR for fingerprinting the mode of action of herbicides by metabolite analysis was by Aranibar et al. (2001). Four modes of action were fingerprinted by using artificial neural networks for classification for ${ }^{1} \mathrm{H}-\mathrm{NMR}$ data from crude extracts of maize. This work was later expanded to 19 modes (Ott et al., 2003). The mode of action of the phytotoxin (5S,8R,13S,16R)-(1)-pyrenophorol was probed in Avena sterilis by using a ${ }^{1} \mathrm{H}-\mathrm{NMR}$ fingerprinting of metabolites (Aliferis and ChysayiTokousbalides, 2006). The fingerprint did not correspond to those of the herbicides diuron, glyphosate, mesotrione, norflurazon, oxadiazon, or paraquat. In Lemna minor, they later claimed that this compound caused effects on the metabolome similar to that of glyphosate, and that their results suggested a similar mode of action (Aliferis et al., 2009), yet they did not check the dramatic elevation in shikimic acid, the telltale marker for inhibition of EPSPS, the target site of glyphosate (Duke et al., 2003). Identification of individual metabolites would have confirmed whether or not this claim was correct. In metabolomic studies of the effects of glyphosate on $A$. thaliana using LC-PDA, LC-MS, and GC-TOFMS (Böttcher et al., 2008) and on Lemna pausicostata using a combination of GC-MS and LC-MS/MS (Grossmann et al., 2012b), large increases in shikimate and effects on amino acid profiles were the predominant early effects of glyphosate. Furthermore, the methods of Böttcher et al. (2008) showed that when a commercial formulation of glyphosate was used, 
the extracts contained significant amounts of formulation chemicals that would not have been discerned with methods that do not separate mixtures into their components. ${ }^{1} \mathrm{H}-\mathrm{NMR}$ analysis of complex mixtures without separation is rapid, but it does not provide clues to the mode of action if the compound profile does not match that of a phytotoxin with a known mode of action. Oikawa et al. (2006) used direct infusion, Fourier transform ion cyclotron resonance mass spectrometry (FT-ICR/MS), another method that does not separate, identify, and quantify metabolites to discriminate between metabolite profiles of four modes of action in $A$. thaliana. Compounds with the same mode of action gave similar results, however, there was overlap between responses to compounds with different modes of action.

Using GC-MS, Kluender et al. (2009) examined the effects of the PSII-inhibiting herbicide prometryn on the metabolites of the green alga Scenedesmus vacuolatus. Results over a 14-h time course showed development of impairment of energy metabolism associated with catabolic processes, and reductions in carbohydrate synthesis. Effects on metabolites preceded effects of the herbicide on growth.

Perhaps the most complete study of the effects of phytotoxins on plant metabolomes is that of Trenkamp et al. (2009) using GC-MS with A. thaliana. They examined the effects of glufosinate, glyphosate, sulcotrione, foramsulfuron, benfuresate, and an experimental cell wall biosynthesis inhibitor AE944. Analysis of polar metabolites revealed clear differences in profiles generated by these compounds with six different modes of action. For some herbicides, the results matched what would be expected from the mode of action of the herbicide (e.g., sulcotrione and AE944), and in other cases there was no apparent connection between the effects on metabolites and the mode of action (e.g., benfuresate). Since benfuresate acts on lipid synthesis, one might not expect to see effects on polar metabolites that would point to a mode of action.

Another example of the use of metabolomics to probe secondary effects of a phytotoxin is that of Cheng et al. (2011), who examined the metabolome of soybean in response to the herbicide lactofen. Herbicides with this mode of action induce host defenses against disease in soybean (Duke et al., 2007). LC-MS analysis of the herbicide-induced metabolites led to the discovery to two new phytoalexins.

Cantrell et al. (2007) examined the effects of the phytotoxic constituents of the roots of Ligularia macrophylla on growth of Lemna paucicostata. Separately, using the chromatography-coupled MS metabolomics methods described in Duke et al. (2011) and Grossmann et al. (2010, 2012a, b), the effects of the most active of these eremophilane compounds, $6 \beta$-angeloyloxy-10 $\beta$-hydroxyfurnoeremophilane, on the metabolome of L. paucicostata were examined (Fig. 4). This method generates relative concentration values for about 200 identified metabolites and 300 unknown compounds. Results are compared by cluster analysis with a proprietary database of about 150 metabolic profiles of previously characterized standard compounds on $L$. paucicostata with about 60 different modes of action (Grossmann et al., 2012b). Strong increases in certain sugars, abscisic acid, L-DOPA, and tryptophan, and decreases in allantoin, aminoallantoins, flavonoids, and cystathionine were observed in response to the furanoermophilane. These effects did not fit any known modes of action. Using this method, Grossmann et al. (2010) found the metabolic profile of saflufenacil to correspond closely to those of PPO inhibitors. This mode of action was confirmed by in vitro enzyme assays and by determining that the compound causes rapid and dramatic increases in protoporphyrin IX in vivo.

The same method was used in conjunction with physionomics to study the mode of action of cinmethylin, an older herbicide with an unknown mode of action (Grossmann et al., 2012a). It is a structural analogue of the potent natural phytotoxin, 1,4-cineole (Romagni et al., 2000). Structurally related 5-benzyloxymethyl-1,2-isoxazolines (ISA) also were studied. In addition to other effects, an ISA caused higher levels of tryptophan and tyrosine, while phenylalanine concentrations were strongly reduced. The tyrosine degradation product L-DOPA (3,4-dihydroxyphenylalanine) increased up to five-fold, and plastohydroquinone levels were reduced. These effects were similar to those of the HPPD inhibitor topramezone, but differed in that the ISA did not cause a decrease in isopentenyl pyrophosphate and tocopherol. Cluster analysis of metabolite changes compared effects of phytoene desaturase, HPPD, and non-mevalonate isoproenoid synthesis inhibitors which have some common effects with cinmethylin and the ISA compounds (Grossmann et al., 2012a) (Fig. 5). Cinmethylin and two ISAs (methiozolin and ISO1) clustered distinctly differently from the other herbicide classes. Feeding treated plants with 4-hydroxyphenylpyruvate (4-HPP), a direct tyrosine derivative, alleviated the growth inhibition (Grossmann et al., 2012a) (Fig. 6). Tyrosine aminotransferase, the enzyme that converts tyrosine to 4-HPP, was inhibited in vitro by cinmethylin and the ISOs. This is the only paper of which we are aware that has used omics methods to discover a new molecular target site.

A more recent paper (Grossmann et al., 2012b) provides considerable metabolomic information using their protocols about a number of known modes of action, as well as new information about a phytotoxic phenylalanine analog (PHE1). Changes in several metabolites, including increases in tryptophan levels, led these researchers to hypothesize that the compound inhibits IAA synthesis. Supplying the plants with IAA and several intermediates of IAA synthesis reversed growth inhibition by PHE1 to a great extent. Analysis of a terrestrial plant treated with 


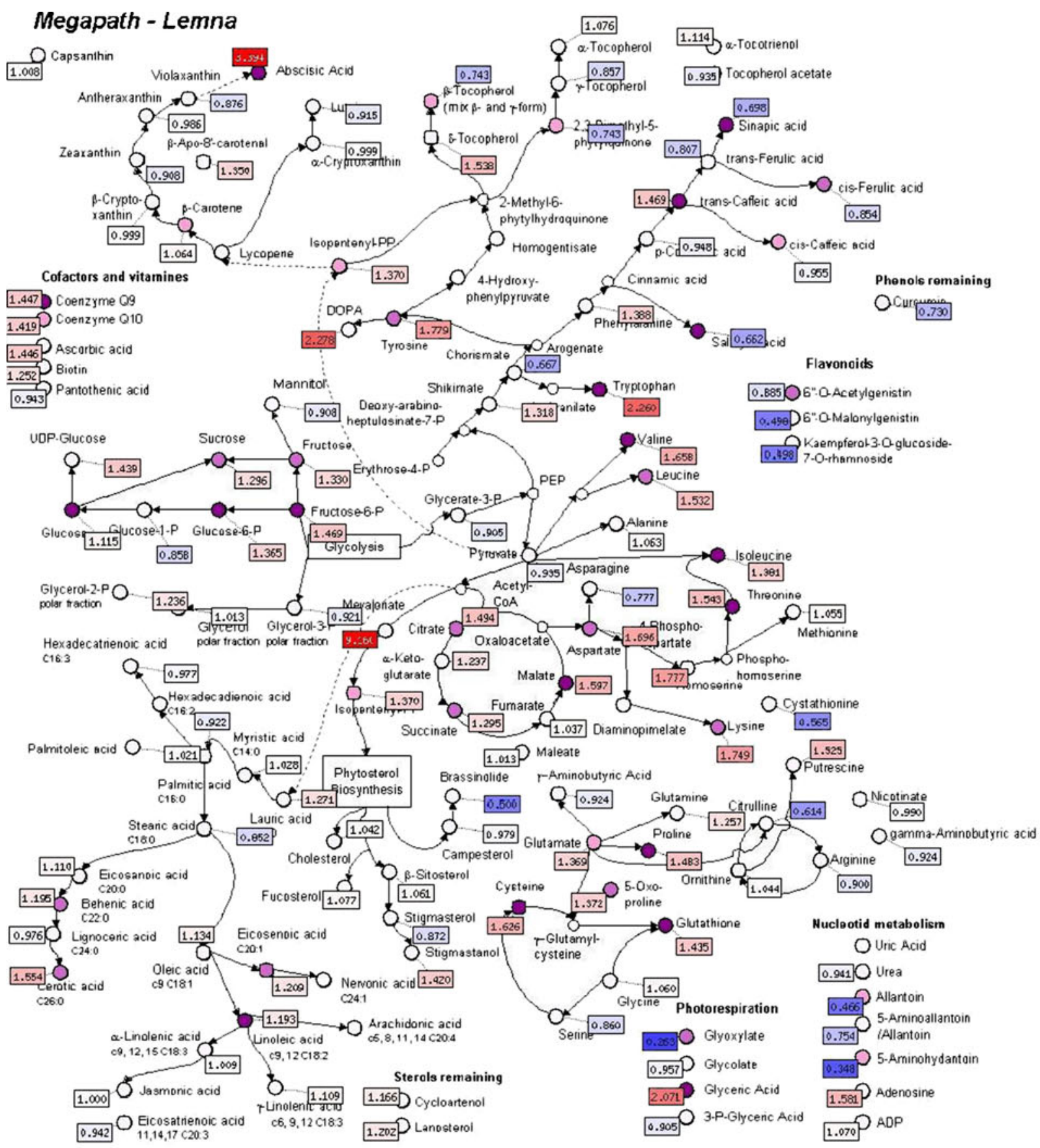

\section{Fatty acid metabolism and related} 0.851 2-Hydroxy-palmitic 0.953 Galactose $0.960 \mathrm{D}$ Phytosphingosine
aciac16 0-OH fraction

1.020 2-Hydroxy-behenic $0.730 \mathrm{D}$ Glucose $0.915 \mathrm{D}$ 1.4-Anhydro

0.777 Cerebronic acid

0.956 Glycerol

0.927 Glycerol-3-P.

0.563 Phosphoothanolamir $0.870 \mathrm{D}$ Serine

E.968 Ethanolamine

T.747 Tetracosanol

1.105 Dodecanol
Glycine

livid traction

0.969 Phosphate
Other sugars and related

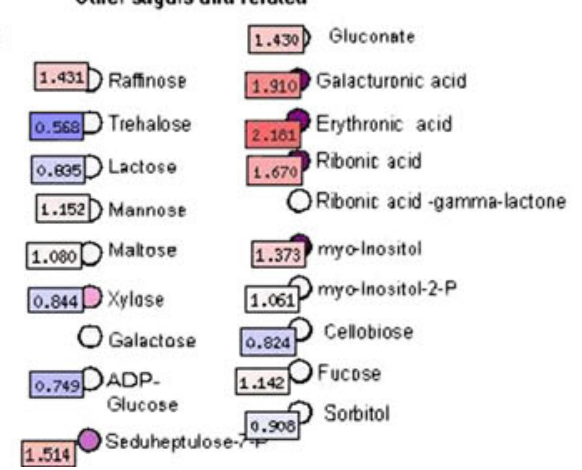

Miscellaneous

1.690 Bisglycerylphosphate

0.948 P Phosphate, $0.994 \mathrm{D}$ Glutarate polar fraction

1.042 Phosponic ac e.000 Zeatin

Sulfamic acid

1.112 D Sulfuric acid

$$
\begin{aligned}
& \text { 3.Hydroxypyridine } \\
& \text { polat traction } \\
& \text { 2.Hydroxypyridine } \\
& \text { lipd troction }
\end{aligned}
$$


Fig. 4 Metabolite profile of Lemna paucicostata treated with $6 \beta$ angeloyloxy-10 $\beta$-hydroxyfurnoermophilane from Ligularia macrophylla. Red flags indicate increases in levels, blue flags indicate decreases in levels. Numerical ratios (treated/untreated) are given within the flags. Nodes of metabolites indicate significance of changes at $P<0.01$ (dark), $0.01<P<0.05$ (middle), or $0.05<P<0.1$ (light) levels. We thank Klaus Grossmann of BASF SE, Limburgerhof, Germany, Charles Cantrell, of USDA, ARS, Oxford, MS, USA, and Nicole Christiansen of Metanomics, Berlin, Germany for these previously unpublished data

PHE1 revealed large decreases in IAA. The enzyme(s) of IAA synthesis that are the most likely the target site(s) have not yet been isolated.

Duke et al. (2011) used the same method to probe the mechanism of action of the potent fungal phytotoxin ascaulitoxin aglycone, produced by the plant pathogen Ascochyta caulina. The metabolic profile did not correspond to any of the 60 modes of action that have been elaborated with this method. However, it caused distinct changes in amino acid contents, which indicated that it might inhibit conversion of pyruvate to alanine or the synthesis and/or interconversion of glutamate/glutamine and aspartate/asparagine. However, in vitro enzyme assays did not confirm either target site.

\section{Physionomics}

Physionomics is based upon profiles of physiological responses to effectors (Grossmann, 2005; Grossmann et al., 2012b). Grossmann (2005) first proposed the term physionomics, and he and his colleagues have used this approach successfully in conjunction with metabolomics to study the mode of action of several compounds (see above). This procedure is similar to past approaches of herbicide

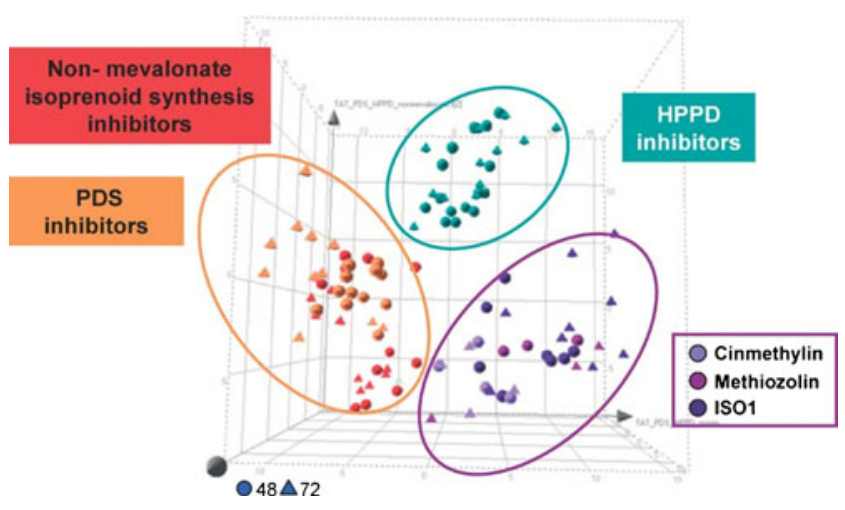

Fig. 5 Mode of action classification by cluster analysis of metabolite changes in Lemna paucicostata 48 and $72 \mathrm{hr}$ after treatment with herbicides affecting isoprenoid synthesis. Three different groupings were found using partial least squares-discriminant analysis. Phytoene desaturase (PDS), hydoxyphenylpyruvate deoxygenase (HPPD), and non-mevalonate isoprenoid synthesis inhibitor modes of action contrast with the results from cinmethylin, methiozolin, and ISO1 (see Fig. 7 for structures). From Grossmann et al. (2012a) with permission discovery by companies for discovery of phytotoxin modes of action, however, the physiological profiles for different modes of action are quantified for clearer comparisons with other and unknown modes of actions with the methods of Grossmann (2005; Grossmann et al., 2012b) (e.g., Fig. 7). Scientists in the public sector have proposed batteries of physiological assays to identify the mode of action of phytotoxins (e.g., Dayan et al., 2000). These physiological assays of the physionomics approach can provide a first clue to a mode of action that in many cases can eliminate the need for more complicated and expensive omics approaches.

\section{Validation}

Omics approaches to mode of action discovery can only point the way to the molecular target of a phytotoxin. Target sites can be partially validated through genetic means, such as determination that a defect in the gene encoding the putative target site generates the same phenotype, including the same omics profile. However, short-term blockage of a biochemical or signaling pathway by a phytotoxin is not likely to cause a similar omics profile as that caused by a genetic defect of the same target. One might expect that if the mutation is not lethal, compensatory mechanisms would have developed. With A. thaliana, knockout mutants are available for essentially every gene of the plant. This includes characterized classical mutants generated by the mutagen ethyl methane sulfonate (EMS) (http://www.arabidopsis.org/) and T-DNA insertion lines (Krysan et al., 1999). However, ultimately, the target site must be validated by showing that it binds the phytotoxin and is inhibited in vitro. With some natural phytotoxins, this can be complicated because the compound is a protoxin; that is, it must be metabolically activated to form the active inhibitor in vivo. Examples of this are the microbial phytotoxin hydantocidin, which must be phosphorylated to inhibit adenylosuccinate synthase (Cseke et al., 1996) and bialaphos, the product of a soil microbe, which must be degraded to phosphinothricin to inhibit glutamine synthetase (Wild and Zeigler, 1989). The strongest validation of a molecular target site of a phytotoxin is a genetic change in the gene of the molecular target site that renders that protein and producing plant resistant.

\section{Problems with and Advantages of Omics Approaches}

Omics technologies lend themselves to "shotgun" experiments with no clear biological rationale, unlike one might have for an experiment with a clear biomarker that predicts cause and effect. The amount of data and complexity of omics studies require complicated analytical capabilities 
Fig. 6 Effects of tyrosine and downstream products of tyrosine amino transferase (4hyroxyphenylpyruvate and homogentisate) on the growth inhibition of Lemna

paucicostata by cinmethylin, methiozolin, and ISO1. From Grossmann et al. (2012a) with permission

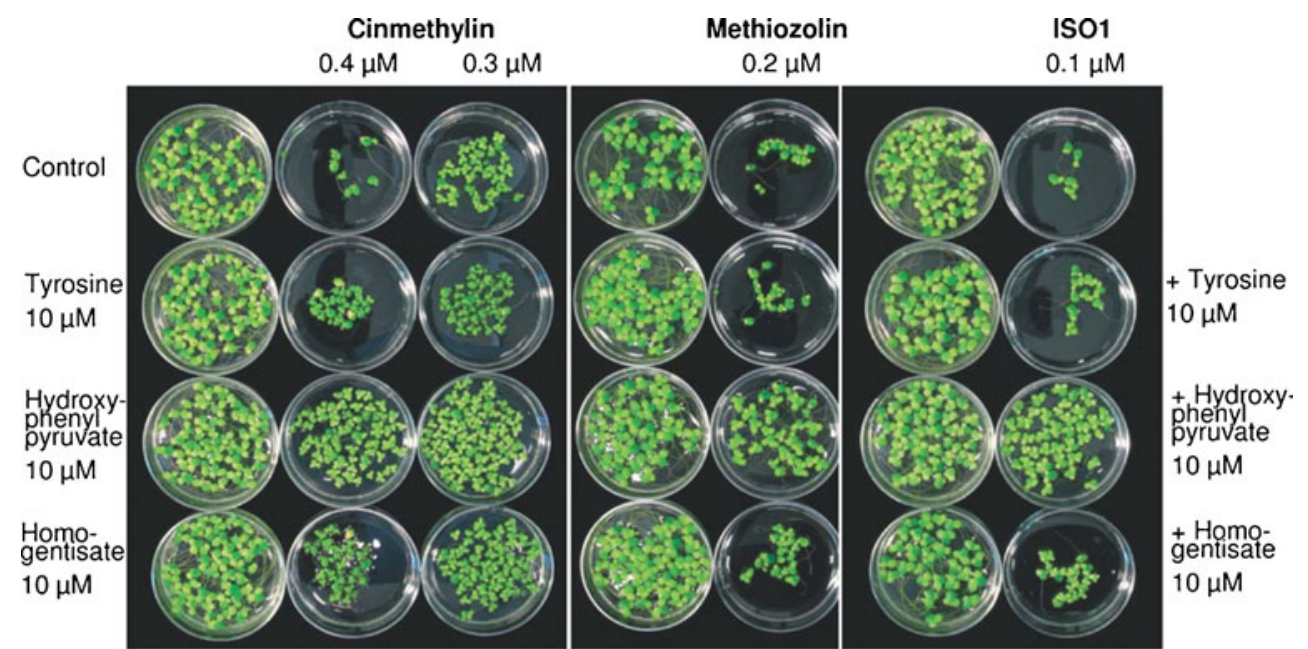

that often do not provide clear answers to biological questions. Even in the most advanced omics work done in the medical field, these problems have been very challenging (Institute of Medicine, 2012). As pointed out by Jamers et al. (2009), the gap between global nucleic acid-based omics (genomics and transcriptomics) and other forms of omics is large in terms of analyzing the complete array of proteins, metabolites, and/or physiological effects. Furthermore, even though modern instrumentation and software has reduced the cost and labor involved in generating and analyzing the huge data bases that are required for rigorous fingerprinting of known modes of action, such an enterprise is still larger than most independent laboratories can bear. Industrial laboratories apparently have generated such databases (e.g., Grossmann et al., 2012b), but the information is largely proprietary.

Nevertheless, omics methods offer greater insight into all of the effects of a phytotoxin on the biochemistry and genetics of a target plant. In addition to seeing how the compound injures the plant, one can answer questions such as mechanisms of defense against the compound (e.g., Baerson et al., 2005), potential secondary target sites (e.g., Zhu et al., 2008), and sublethal effects on plant constituents. Considering that these technologies are only about a decade old, we have only begun to fully employ them to answer questions related to natural phytotoxins and chemical ecology.

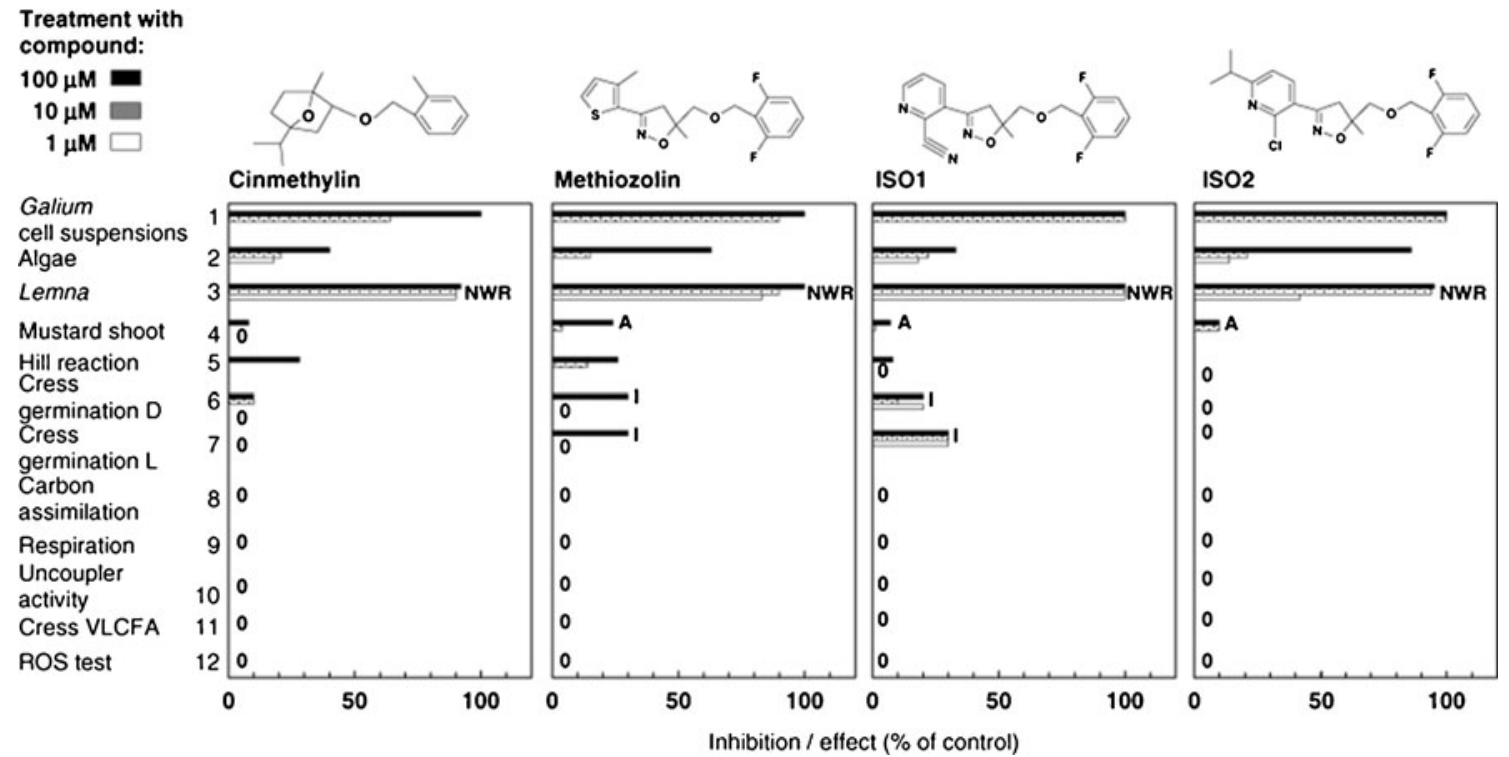

Fig. 7 Physionomic profiles of four compounds that are apparently phytotoxic due to inhibition of tyrosine amino transferase. Bioassay abbreviations: D, dark; L, light; VLCFA, very long chain fatty acid; ROS, reactive oxygen species. Symptoms observed: A, tissue desiccation; I, root growth inhibition; N, necrosis of meristematic area; $\mathrm{WR}$, intensified green leaf pigmentation. Reproduced with permission from Grossmann et al. (2012a) 
Open Access This article is distributed under the terms of the Creative Commons Attribution License which permits any use, distribution, and reproduction in any medium, provided the original author(s) and the source are credited.

\section{References}

Abbas, H. K., Duke, S. O., SheIR, W. T., and Duke, M. V. 2002. Inhibition of ceremide synthesis in plants by phytotoxins, pp. 211-219, in R. K. Upadhyay (ed.), Advances in Microbial Toxin Research and it Biochemical Exploitation. Kluwer Academic/ Plenum, London.

Abdallah, C., Dumas-Gaudot, E., Renaut, J., and Sergeant, K. 2012. Gel-based and gel-free quantitative proteomics approaches at a glance. Int. J. Plant Genomics. 2012:Article ID 494572, 17 p.

Aliferis, K. A. and ChYSAYI-TokousBalides, M. 2006. Metabolomic strategy for the investigation of the mode of action of the phytotoxin $(5 S, 8 R, 13 S, 16 R)$-(1)-pyrenophorol using nuclear magnetic resonance fingerprinting. J. Agric. Food Chem. 54:1687-1692.

Aliferis, K. A. and ChYSAYI-TOKOUSBalides, M. 2011. Metabolomics in pesticide research and development: Review and future perspectives. Metabolomics 7:35-53.

ALIFERIS, K. A. and JABAJI, S. 2011. Metabolomics-a robust bioanalytical approach for the discovery of the modes of action of pesticides: A review. Pestic. Biochem. Physiol. 100:105-117.

Aliferis, K. A., MaterzoK, S., Paziotou, G. N., and ChysayiTOKOUSBALIDES, M. 2009. Lemna minor L. as a model organism for ecotoxicological studies performing ${ }^{1} \mathrm{H}$ NMR fingerprinting. Chemosphere 76:967-973.

Aranibar, N., Singh, B. J., Stockton, G. W., and Ott, K. H. 2001. Automated mode of action detection by metabolic profiling. Biochem. Biophys. Res. Commun. 286:150-155.

Baerson, S. R., SÁnchez-Moreiras, A., Pedrol-Bonjoch, N., Schulz, I. A., Kagan, A. K., Reigosa, M. J., and Duke, S. O. 2005. Detoxification and transcriptome response in Arabidopsis seedlings exposed to the allelochemical benzoxazolin-2(3H)-one (BOA). J. Biol. Chem. 280:21867-21881.

BAJSA, J., PAN, Z., and DuKE, S. O. 2011a. Transcriptional responses to cantharidin, a protein phosphatase inhibitor, in Arabidopsis thaliana reveal the involvement of multiple signal transduction pathways. Physiol. Plant. 143:188-205.

BAJSA, J., PAN, Z., and DUKE, S. O. 2011b. Serine/threonine protein phosphatases: Multi-purpose enzymes in control of defense mechanisms. Plant Signal. Behav. 6:1921-1925.

BajSA, J., PAN, Z., DAYAN, F. E., OWENS, D. K., and DuKe, S. O. 2012. Validation of serine/threonine protein phosphatase as the herbicide target site of endothall. Pestic. Biochem. Physiol. 102:38-44.

Beaudegnies, R., Edmunds, A. J. F., Fraser, T. E. M., Hall, R. G., Hawkes, T. R., Mitchell, G., Schaetzer, J., Wendeborn, S., and WIBLEY, J. 2009. Herbicidal 4-hydroxyphenylpyruvate dioxygenase inhibitors - a review of the triketone chemistry story from a Syngenta perspective. Bioorg. Med. Chem. 17:4134-4154.

Bharucha, N. and Kumar, A. 2007. Yeast genomics and drug target identification. Comb. Chem. High Throughput Screen. 10:618-634.

BINDSCHEDLER, L. V. and CRAMER, R. 2011. Quantitative plant proteomics. Proteomics 11:756-775.

Böttcher, C., Centeno, D., Freitag, J., Höfgen, R., Köhl, K., Kopka, J., KroymanN, J., Matros, A., Mock, H.-P., NeUmanN PFAlZ, M., VON ROEPENACK-LAHAYE, E., SCHAUER, N., TRENKAMP, S., Zurbriggen, M., and Fernie, A. R. 2008. Teaching (and learning from) metabolomics: The 2006 PlantMetaNet ETNA metabolomics research school. Physiol. Plant. 132:136-149.

Cantrell, C. L., Duke, S. O., Fronczek, F. R., OsbrinK, W. L. A., Mamonov, L. K., VAssilyeV, J. I., Wedge, D. E., and Dayan, F.
E. 2007. Phytotoxic eremophilanes from Ligularia macrophylla. J. Agric. Food Chem. 55:10656-10663.

Castro, A. J., Carapito, C., Zorn, N., Magne, C., Leize, E., Van Dorsselaer, A., and Clement, C. 2005. Proteomic analysis of grapevine (Vitis vinifera L.) tissues subjected to herbicide stress. J. Exp. Bot. 56:2783-2795.

Cheng, J., Yuan, C., and Graham, T. L. 2011. Potential defenserelated prenylated isoflavones in lactofen-induced soybean. Phytochemistry 72:875-881.

ChI, W. C., Fu, S.-F., Huang, T.-L., Chen, Y.-A., Chen, C.-C., and HUANG, H.-J. 2011. Identification of transcriptome profiles and signaling pathways for the allelochemical juglone in rice roots. Plant Mol. Biol. 77:591-607.

Cruz-Ortega, R., Romero-Romero, T., Ayala-Cordero, G., and ANAYA, A. L. 2004. Proteomic techniques for the study of allelopathic stress produced by some Mexican plants on protein patterns in bean and tomato roots, pp. 271-287, in A. Macías, J. C. G. Galindo, J. M. G. Molinillo, and H. G. Cutler (eds.), Allelopathy: Chemistry and Mode of Action of Allelochemical. CRC Press, Boca Raton, FL, USA.

Cseke, C., Gerwick, B. C., Crouse, G. D., Murdoch, M. G., Green, S. B., and Heim, D. R. 1996. $2 \alpha$-Phosphohydantocidin: The in vivo adenylosuccinate synthetase inhibitor responsible for hydantocidin phytotoxicity. Pestic. Biochem. Physiol. 55:210 217.

DAs, M., Reichman, J. R., HABERER, G., Welzl, G., Aceituno, F. F., Mader, M. T., Watrud, L. S., Pfleeger, T. G., Gutiérrez, R. A., SCHÄFFnER, A. R., and OlsZYK, D. M. 2010. A composite transcriptional signature differentiates responses towards closely related herbicides in Arabidopsis thaliana and Brassica napus. Plant Mol. Biol. 72:545-556.

DAYAN, F. E. and WATSON, S. B. 2011. Plant cell membrane integrity as a marker for light-dependent and light-independent mechanisms of action. Pestic. Biochem. Physiol. 101:182-190.

DAYAN, F. E. and ZACCARO, M. L. 2012. Chlorophyll fluorescence as a marker for herbicide mechanisms of action. Pestic. Biochem. Physiol. 102:189-197.

DaYAN, F. E., ROMAGNi, J. G., and DuKE, S. O. 2000. Investigating the mode of action of natural phytotoxins. J. Chem. Ecol. 26:2079-2094.

DAYAN, F. E., OWEnS, D. K., and DuKE, S. O. 2012. Rationale for a natural products approach to herbicide discovery. Pest Manag. Sci. 68:519-528.

DiXON, R. A. 2001. Natural products and plant disease resistance. Nature 411:843-847.

DukE, S. O. 2012. Why have no new herbicide modes of action appeared in recent years? Pest Manag. Sci 68:505-512.

DUKE, S. O. and DAYAN, F. E. 2011. Modes of action of microbiallyproduced phytotoxins. Toxins 3:1038-1064.

DuKE, S. O., BAERSON, S. R., and RIMANDO, A.M. 2003. Herbicides: Glyphosate, in J. R. Plimmer, D. W. Gammon and N. N. Ragsdale (eds) Encyclopedia of Agrochemicals. John Wiley \& Sons, New York. http://www.mrw.interscience.wiley.com/eoa/articles/ agr119/frame.html.

Duke, S. O., Wedge, D. E., Cerdeira, A. L., and Matallo, M. B. 2007. Interactions of synthetic herbicides with plant disease and microbial herbicides, pp. 277-296, in M. Vurro and J. Gressel (eds.), Novel Biotechnologies for Biocontrol Agent Enhancement and Management. Springer, Dordrect, The Netherlands.

Duke, S. O., BAerson, S. R., and Gressel, J. 2009. Genomics and weeds: A synthesis, pp. 221-247, in C. N. Stewart (ed.), Weeds and Invasive Plant Genomics. Wiley-Blackwell, Singapore.

DukE, S. O., Evidente, A., FIORE, M., RiMando, A. M., DAYAN, F. E., Vurro, M., Chistiansen, N., LoOser, R., Hutzler, J., AND GROSSMANN, K. 2011. Effects of the aglycone of ascaulitoxin on amino acid metabolism in Lemna paucicostata. Pestic. Biochem. Physiol. 100:41-50. 
FeDTKE, C. and Duke, S. O. 2005. Herbicides, pp. 247-330, in B. Hock and E. F. Elstner (eds.), Plant Toxicology. Marcel Dekker, New York.

Gardiner, S. A., Boddu, J., Berthiller, F., Hametner, C., Stupar, R. M., AdAm, G., and Muehlbauer, G. J. 2010. Transcriptome analysis of the barley-deoxynivalenol interaction: Evidence for a role of glutathione in deoxynivalenol detoxification. Mol. Plant Microbe Interact. 23:962-976.

Gershater, M. C., CUMmins, I., and Edwards, R. 2007. Role of carboxylesterase in herbicide bioactivation in Arabidopsis thaliana. J. Biol. Chem. 282:21460-21466.

Glombitza, S., Dubuis, P. H., Thulke, O., Welzl, G., Bovet, L., Götz, M., AfFenzeller, M., Geist, B., Hehn, A., Asnaghi, C., ERnSt, D., Seidlitz, H. K., Gundlach, H., Mayer, K. F., MarTIONOIA, E., WERCK-REICHHART, D., MAUCH, F., and SCHÄFFNER, A. R. 2004. Crosstalk and differential response to abiotic and biotic stressors reflected at the transcriptional level of effector genes from secondary metabolism. Plant Mol. Biol. 54:817-835.

GOBERT, G. N. and JONES, M. K. 2008. Discovering new schistosome drug targets: The rolf of transcriptomics. Curr. Drug Targets 9:922-930.

Golisz, A., Sugano, M., and FuJII, Y. 2008. Microarray expression profiling of Arabidopsis thaliana L. in response to allelochemicals identified in buckwheat. J. Exp. Bot. 59:3099-3109.

Golisz, A., Sugano, M., Hiradate, S., and FujiI, Y. 2011. Microarray analysis of Arabidopsis plants in response to the allelochemical L-DOPA. Planta 233:231-240.

GRESSEL, J. 2009. Arabidopsis is not a weed, and mostly not a good model for weed genomics; there is no good model for weed genomics, pp. 25-32, in C. N. Stewart (ed.), Weeds and Invasive Plant Genomics. Wiley-Blackwell, Singapore.

GrossmanN, K. 2005. What it takes to get a herbicide's mode of action. Physionomics, a classical approach in a new complexion. Pest Manag. Sci 61:423-431.

Grossmann, K., Niggeweg, R., Chrisiansen, N., Looser, R., and EHRHARDT, T. 2010. The herbicide saflufenacil (Kixor ${ }^{\mathrm{TM}}$ ) is a new inhibitor of protoporphyrinogen IX oxidase activity. Weed Sci. 58:1-9.

Grossmann, K., Hutzler, J., Tresch, S., Chrisiansen, N., LoOser, R., and EHRHARDT, T. 2012a. On the mode of action of the herbicides cinmethylin and 5-benzyloxymethyl-1,2-isoxazolines: Putative inhibitors of plant tyrosine aminotransferase. Pest Manag. Sci. 68:482-492.

Grossmann, K., Chrisiansen, N., Looser, R., Tresch, S., Hutzler, J., Pollmann, S., and EhrHardT, T. 2012b. Physionomics and metabolomics-two key approaches in herbicidal mode of action discovery. Pest Manag. Sci. 68:494-504.

Holmes, P., Farquharson, R., Hall, P. J., and Rolfe, B. G. 2006. Proteomic analysis of root meristems and the effects of acetohydroxyacid synthase-inhibiting herbicides in the root of Medicago truncatula. J. Proteome Res. 5:2309-2316.

InSTITUTE OF MEDICINE 2012. Evolution of translational omics: Lessons learned and the path forward. The National Academies Press, Washington, D.C.. 338 p.

JAMERS, A. and DE COEN, W. 2010. Effect assessment of the herbicide paraquat on green alga using different gene expression and biochemical markers. Environ. Toxicol. Chem. 29:893-901.

Jamers, A., Blust, R., and DE COEN, W. 2009. Omics in algae: Paving the way for a systems biological understanding of algal stress phenonmena? Aquat. Toxicol. 92:114-121.

Kagan, I. A., Michel, A., Prause, A., Scheffler, B. E., Pace, P., and DUKE, S. O. 2005. Gene transcription profiles of Saccharomyces cerevisiae after treatment with plant protection fungicides that inhibit ergosteroal biosynthesis. Pestic. Biochem. Physiol. 82:133-153.

Kelley, K. B., Zhang, Q., Lambert, K. N., and Riechers, D. E. 2006. Evaluation of auxin-responsive genes in soybean for detection of off-target growth regulator herbicides. Weed Sci. $54: 220-229$.

Kluender, C., SANS-PichÉ, F., RiedL, J., Altenburger, R., HAERTiG, C., LAUe, G., and Schmitt-Jansen, M. 2009. A metabolomics approach to assessing phytotoxic effects on the green alga Scenedesmus vacuolatus. Metabolomics 5:59-71.

Krysan, P. J., Young, J. C., and Sussman, M. R. 1999. T-DNA as insertional mutagen in Arabidopsis. Plant Cell 11:2283-2290.

LAHM, G. P., CORDOVA, D., and BARRY, J. D. 2009. New and selective ryanodine receptor activators for insect control. Bioorg. Med. Chem. 17:4127-4133.

Lechelt-Kunze, C., Meissner, R. C., Drewes, M., and Tietjen, K. 2003. Flufenacet herbicide treatment phenocopies the fiddlehead mutant in Arabidopsis thaliana. Pest Manag. Sci. 59:847856.

LI, Z.-F., ZhANG, Z.-G., XIE, D.-F., DAI, L.-Q., ZHU, L.-F., LI, J., LIU, Z.-Q., YANG, Y.-Q., WU, L.-K., HuANG, M.-J., ZHANG, Z.-Y., and LIN, W.-X. 2011. Positive allelopathic stimulation and underlying molecular mechanism of achyranthe under continuous monoculture. Acta Physiol. Plant. 33:2339-2347.

Manabe, Y., TinKer, N., Colville, A., and Miki, B. 2007. CSR1, the sole target site of imidazolinone herbicide in Arabidopsis thaliana. Plant Cell Physiol. 48:1340-1358.

Manfield, I. W., Orfila, C., McCartney, L., Harholt, J., Bernal, A. J., Scheller, H. V., Gilmartin, P. M., Mikkelsen, J. D., KNOX, J. P., and Willats, W. G. T. 2004. Novel cell wall architecture of isoxaben-habituated Arabidopsis suspension cultured cells: Global transcript profiling and cellular analysis. Plant J. 40:260-275.

Marioni, J. C., Mason, C. E., Mane, S. M., Stephens, M., and GILAD, Y. 2008. RNA-seq: An assessment of technical reproducibility and comparison with gene expression arrays. Genome Res. 18:1509-1517.

Morozova, O. and Marra, M. A. 2008. Applications of nextgeneration sequencing technologies in functional genomics. Genomics 92:256-264.

Nestler, H., Groh, K. J., Schönenberger, R., EgGen, R. I. L., and SUTER, M. J.-F. 2012. Linking proteome responses with physiological and biochemical effects of herbicide-exposed Chlamydomonas reinhardtii. J. Proteome 75:5370-5385.

Oikawa, A., Nakamura, Y., Ogura, T., Kumura, A., SuzUKi, H., SaKurai, N., ShInbo, Y., Shibata, D., KanaYa, S., and OHTA, D. 2006. Clarification of pathway-specific inhibition by Fourier transform ion cyclotron resonance/mass spectrometry-base metabolic phenotyping studies. Plant Physiol. 142:398-413.

Ott, K.-H., Aranibar, N., Singh, B., and Stockton, G. W. 2003. Metabolomics classifies pathways affected by bioactive compounds. Artificial neural network classification of NMR spectra of plant extracts. Phytochemistry 62:971-985.

Pan, Z., Agarwal, A. K., Xu, T., Feng, O., Baerson, S. R., and Duke, S. O. 2008. Identification of molecular pathways affected by pterostilbene, a natural dimethylether analog of resveratrol, in Saccharomyces cerevisiae. BMC Med. Genet. 1:7. doi:10.1186/1755-8794-1-7.

Pasquer, F., OChSNER, U., ZARN, J., and Keller, B. 2006. Common and distinct gene expression patterns induced by the herbicides 2,4-dichlorophenoxyacetic acid, cinidon-ethyl and tribenuronmethyl in wheat. Pest Manag. Sci. 62:1155-1167.

Raghavan, C., Ong, E. K., Dalling, M. J., and Stevenson, T. W. 2005. Effect of herbicidal application of 2,4-diclorophenoxyacetic acid in Arabidopsis. Funct. Integr. Genom. 5:60-70.

Raghavan, C., Ong, E. K., Dalling, M. J., and Stevenson, T. W. 2006. Regulation of genes associated with auxin, ethylene and ABA pathways by 2,4-dichlorophenoxyacetic acid in Arabidopsis. Funct. Integr. Genom. 6:60-70.

Ramel, F., Sulmon, C., Cabello-Hurtado, F., Tacconat, L., Martin-Magniette, M.-L., Renou, J.-P., El Amrani, A., 
CoueE, I., and Gouesbet, G. 2007. Genome-wide interacting effects of sucrose and herbicide-mediated stress in Arabidopsis thaliana: Novel insights into atrazine toxicity and sucroseinduced tolerance. BMC Genomics 8:450.

Redman, J. C., HaAs, B. J., TAnimoto, G., and Christopher, D. 2004. Development and evaluation of an Arabidopsis whole genome Affymetrix probe array. Plant J. 38:545-561.

Romagni, J. G., Allen, S. N., and Dayan, F. E. 2000. Allelopathic effects of volatile cineoles on two weedy plant species. J. Chem. Ecol. 26:303-313.

SkADSEN, R. W. and Jing, P. 2008. Transcriptome profile of barley aleurone differs between total and polysomal RNAs: Implications for proteome modeling. Mol. Breeding 21:261-269.

Skipsey, M., KNIGHT, K. M., BrZIER-Hicks, M., DiXon, D. P., PATrick, G., and EDWARDS, R. 2011. Xenobiotic responsiveness of Arabidopsis thaliana to a chemical series derived from a herbicide safener. J. Biol. Chem. 286:32268-32276.

Trenkamp, S., EcKes, P., Busch, M., and Fernie, A. R. 2009. Temporarily resolved GC-MS-based metabolic profiling of herbicide treated plants reveals that changes in polar primary metabolites alone can distinguish herbicides of differing mode of action. Metabolomics 5:277-291.

TRIMPIN, S. and BRIZZARD, B. 2009. Analysis of insoluble proteins. Biotechniques 46:321-326.

Uppalapati, S. R., Ayoubi, P., Weng, H., Palmer, D. A., Mitchell, R. E., Jones, W., and BENDER, C. L. 2005. The phytotoxin coronatine and methyl jasmonate impact multiple phytohormone pathways in tomato. Plant J. 42:201-217.

WANG, Z., GERSTEIN, M., and SNYDER, M. 2009. RNA-Seq: A revolutionary tool for transcriptomics. Nature Rev. Gen. 10:57-63.

WANG, Z., LI, Q., ZHAO, J., and PENG, Y. 2011. Investigation of the effect of amiprophos methyl on spindle formation and proteome change in maize by immunofluorescence and proteomic technique. Cytologia 76:249-259.

WiLD, A. and Zeigler, C. 1989. The effect of bialaphos and ammonium on ammonioum-assimilation and photosynthesis. I. Effects on the enzymes of ammonia-assimilation. Z. Naturforsch. 44C:97-102.

ZHANG, Q. and RIECHERS, D. E. 2008. Proteomics: An emerging technology for weed science research. Weed Sci. 56:306-313.

ZhANG, Q., QIN, X., LAMBERT, K. N., and RIEChers, D. E. 2007. Safeners coordinately induce the expression of multiple proteins and MRP transcripts involved in herbicide metabolism and detoxification in Triticum tauschii seedling tissues. Proteomics 7:1261-1278.

Zhu, J., Patzoldt, W. L., Shealy, R. T., Vodkin, L. O., Clough, S. J., and TRANEL, P. J. 2008. Transcriptome response to glyphosate in sensitive and resistant soybean. J. Agric. Food Chem. 56:6355-6363.

Zhu, J., Patzoldt, W. L., Radwan, O., Tranel, P. J., and Clough, S. J. 2009. Effects of photosytem II-interfering herbicides atrazine and bentazon on the soybean transcriptome. Plant Genome 2:191-205. 